\title{
UNIDADES FRASEOLÓGICAS COM ZOÔNIMOS: APRESENTAÇÃ̃ E LOCALIZAÇÃO EM DICIONÁRIOS MONOLÍNGUES E EQUIVALENTES DE TRADUÇÃO EM DICIONÁRIOS BILÍNGUES
}

\author{
Rosana Budny* \\ Adja Balbino de Amorim Barbieri Durão*
}

\begin{abstract}
Resumo: Este trabalho apresenta parte de uma pesquisa na qual se investiga, por um lado, a presença de unidades fraseológicas com zoônimos nos dicionários Houaiss e Borba e, por outro, seus equivalentes de tradução em dicionários bilíngues português-inglês/inglês-português. Os dicionários bilíngues escolhidos como fonte da pesquisa foram os que são encontrados com maior frequência entre os estudantes, e portanto os que têm acesso fácil. $\mathrm{O}$ objetivo da pesquisa é averiguar como as unidades fraseológicas com zoônimos são registradas (localização e apresentação) nesses dicionários e comparar os equivalentes oferecidos nos diferentes dicionários bilíngues avaliados, identificando desse modo diferenças e/ou omissões. Justifica esta proposta a tentativa de provar, dependendo dos problemas identificados, que as informações oferecidas nesses dicionários não são suficientes para suprir as necessidades formativas dos aprendizes que buscam apoio neles para suas produções.

Palavras-chave: Lexicografia; unidades fraseológicas com zoônimos (UFz); dicionários bilíngues; produção.
\end{abstract}

* Universidade Federal de Santa Catarina. 


\begin{abstract}
This paper presents part of a survey in which is investigated the presence of phraseological units with zoonims in the dictionaries Houaiss and Borba and also their translation equivalents in bilingual dictionaries Portuguese-English/ Portuguese. The bilingual dictionaries chosen are those most commonly found among students and therefore more easily accessed in bookstores. The objective of the research is to discover how the phraseological units with zoonims (which we will nominate UFz) are recorded (location and presentation) in the dictionaries Houaiss and Borba and to compare the equivalents offered in those bilingual dictionaries, thereby identifying dissimilarities and / or omissions. This proposal is justified by the understanding that, depending on the problems identified, the information provided in these dictionaries do not meet the training needs of learners who seek support on them for their productions.
\end{abstract}

Keywords: Lexicography; phraseological units with zoonims (UFz); bilingual dictionaries; production.

\title{
Introdução
}

Neste trabalho tomam-se dois dicionários monolíngues da língua portuguesa e sete dicionários bilíngues (portuguêsinglês-português) como fonte de pesquisa, o que permitirá que se identifiquem as unidades fraseológicas que contêm zoônimos (palavras que nomeiam animais - doravante UFz), assim como o tratamento dado a elas nesses dicionários. Comparam-se as informações presentes nesses dicionários, e também constata-se a omissão de alguns itens desse tipo nesses repertórios lexicográficos.

Hartmann (2007, p. 15), concordando com Snell-Hornby (1983), afirma que os autores de dicionários bilíngues não devem confiar "na ilusão de equivalência existente entre lexemas, mas na percepção de que o que realmente há na comparação interlinguística é uma cobertura parcial e não equivalência total". Hartmann não acredita na possibilidade de equivalência total entre as línguas, daí a defender que a equivalência deveria ser 
subdividida em classes (que iriam da "equivalência total" a "ausência de correspondência"). Hartmann explica que ainda não há uma metodologia consistente que torne o trabalho do lexicógrafo menos intuitivo, de modo que algumas soluções encontradas pelos lexicógrafos, no tocante à proposição de equivalentes, têm um "quê" de artificial e "irreal", pois muitas vezes as palavras lematizadas nesse tipo de dicionário são despidas de seus contextos colocacionais, flexionais e derivacionais, oferecendo-se como critério para a equivalência léxica uma "correspondência estática de palavras".

Os direcionamentos sugeridos por Bejóint (1994), Hartmann (2001, 2007), Welker (2004) e Werner e Durão (2012), entre outros pesquisadores, servem de base para a presente pesquisa, que tem o propósito de verificar se as necessidades de produção dos usuários potenciais desse tipo de dicionários estão sendo atendidas no que se refere às UFz nos tipos de dicionários antes referidos.

\section{Tradições linguísticas da lexicografia}

Béjoint (1994, p. 169) relata que, de maneira geral, os lexicógrafos sempre foram linguistas, de alguma forma, muito embora eles mesmos não se considerassem linguistas, nem mesmo assumissem trazer contribuições da linguística para o seu trabalho. Na França e na Grã-Bretanha, nos séculos XIX e XX, os linguistas não costumavam interessar-se por dicionários, a não ser como fonte de consulta e pesquisa de línguas exóticas. Considerava-se, então, o dicionário geral como produto comercial, sem inovações desde suas origens, e como material de consulta desprovido de fundo linguístico. Rey (1982, p. 17, apud Béjoint 1994, p.169) explica que o dicionário era visto com desinteresse pela academia, por ser um produto "não científico" e "impuro".

Os lexicógrafos e editores de dicionários não viam a necessidade de aplicar pressupostos da linguística às suas obras, 
por não verem utilidade prática nessa aplicação. No entanto, apesar das dificuldades dos primeiros contatos, na França e na GrãBretanha, entre os anos 1940 e 1960, começou a se evidenciar um interesse pela linguística por parte dos lexicógrafos, e dos linguistas pelo estudo e desenvolvimento de dicionários. Iniciava-se uma nova etapa em que a linguística contribuiria para o aperfeiçoamento dos dicionários e a lexicografia veria a aplicação linguística como solução para inúmeros problemas de seu campo de trabalho.

\section{O dicionário bilíngue, gênese medieval e funções na atualidade}

Os dicionários bilíngues têm sido úteis para pessoas que precisam falar línguas estrangeiras e precisam estar em constante atualização. Na elaboração dos dicionários, os lexicógrafos podem se valer dos resultados das pesquisas para adequar esses materiais para as diversas funções que eles precisam desempenhar.

Werner e Durão (2012) lembram que há muito tempo arrastam-se na bibliografia dicotomias sobre teoria do dicionário bilíngue. Essas dicotomias consistem em: (1) duas possíveis funções do dicionário bilíngue, uma ativa e outra passiva, que correspondem, pelo menos, a dois tipos de dicionário: um destinado à recepção e outro à produção; e (2) caracterização do dicionário bilíngue, como dicionário de equivalências, e qualificação do dicionário monolíngue como dicionário explicativo ou de definições.

Werner e Durão (2012) chamam a atenção para o fato de que é preciso levar em consideração as distinções existentes entre (1) dicionários de consulta usados como ferramentas para a solução de problemas de recepção ou de produção e (2) dicionários bilíngues didáticos, concebidos para a aquisição de uma língua que não é a língua materna do usuário e para a aprendizagem sistemática de línguas estrangeiras. 
Werner e Durão (2012) esclarecem ser comum pensar que os dicionários monolíngues são melhores para a aprendizagem de línguas estrangeiras que os dicionários bilíngues, mas segundo esses estudiosos "há fortíssimos argumentos em favor da elaboração e do uso de dicionários bilíngues destinados a falantes de línguas maternas específicas". Além disso, como destaca Welker (2004, p. 194), "há vários aspectos em que os dicionários bilíngues diferem muito pouco dos monolíngues". Com relação aos dicionários bilíngues, Werner e Durão (2012) defendem o ponto de vista de que:

Os dicionários bilíngues, muito especialmente os que têm função didática, não devem ser concebidos, em primeiro lugar, como dicionários de equivalências, mas devem ser planejados como dicionários contrastivos, ou seja, devem destacar não a equivalência entre as expressões da língua de partida e as da língua de destino que compartilhem traços formais, semânticos e pragmáticos com aquelas, mas proporcionar ampla informação diferenciadora. Dicionários deste tipo seriam sumamente úteis no caso de línguas genética e estruturalmente próximas, especialmente quando se trata de dicionários de aprendizagem. (WERNER E DURÃO, 2012).

Esses estudiosos acreditam que dicionários de tipo contrastivo, especialmente dicionários de aprendizagem, podem proporcionar instrução lexicográfica relevante a partir das afinidades interlinguísticas existentes nas línguas do dicionário, ou seja, itens que poderiam ser transferidos de forma produtiva e também elementos que poderiam ser transferidos de forma negativa de uma língua a outra.

\section{O dicionário bilíngue e a equivalência}

A questão da equivalência é tema discutido por vários linguistas e lexicógrafos. Em função das restrições de espaço do 
presente artigo, centraremos nossos comentários nas reflexões que giram em torno da ausência de equivalentes totais no dicionário bilíngue.

\subsection{Ausência de equivalentes totais no dicionário bilíngue}

Carvalho (2001, p.117-118) chama a atenção para o fato de que vários teóricos da tradução vêm propondo alternativas para o problema da ausência de equivalência total, oferecendo alternativas para lidar com a questão.

No entanto, sabe-se que esse problema é de difícil solução por causa da idiossincrasia de cada língua. Welker (2004, p.196197) afirma que há diferentes aspectos a serem averiguados na tentativa de verificar as limitações específicas da proposição de equivalentes, relacionados a uma análise:

- estilística (mesmo registro);

- pragmática (o equivalente deve poder ser usado nas mesmas situações de comunicação que o lema);

- terminológica (um termo técnico deve ser traduzido por outro termo técnico na LE);

- diacrônica (um lexema antiquado deve ser traduzido por um lexema antiquado na L2);

- contextual (o equivalente deve poder ser usado nos mesmos co(n)textos que o lema);

- sintático-gramatical (o equivalente deve poder ser usado nas mesmas estruturas sintáticas [por exemplo, na voz passiva]);

- metafórica (uma metáfora deve ser traduzida por outra metáfora na LE);

- etimológica (deve-se preferir equivalentes que têm a mesma origem do lexema da LM). 
Em vista da dificuldade de encontrar equivalentes totais de tradução, não se deve esperar mais dos dicionários do que eles podem dar, ainda que sem perder de vista que o papel de um bom dicionário é apresentar equivalentes e explicitar suas condições de uso.

\section{As expressões idiomáticas - duas definições}

Tagnin (1989, p.13) propõe uma definição de expressão idiomática (EI), dizendo que uma expressão "é idiomática apenas quando seu significado não é transparente, isto é, quando o significado da expressão toda não corresponde à somatória do significado de cada um de seus elementos". Tagnin dá como exemplo a expressão bater as botas, que no português brasileiro não significa "dar pancadas com calçado que envolve o pé e parte da perna", mas "morrer".

Tagnin também explica que o termo idiomático é uma noção que pode gerar mal-entendidos, uma vez que os brasileiros o tomam por "vernáculo, próprio da língua". Para que se entenda o sentido de idiomático na unidade fraseológica "expressões idiomáticas", esse termo deve significar "não transparente" ou "opaco", diferentemente da ideia de idiomático como "vernáculo".

Xatara $(1998$, p. 2) define expressão idiomática como uma "lexia complexa indecomponível, conotativa e cristalizada em um idioma pela tradição cultural." Essa estudiosa explica que a expressão idiomática é uma lexia complexa por poder ter a forma de uma unidade locucional ou frasal; indecomponível, por ter distribuição única ou restrita; conotativa, por ter uma interpretação semântica como um todo que não considera os significados de cada palavra; e, finalmente, cristalizada, por ter significação e frequência de emprego estáveis, que a estabelece como tal.

Apresentadas essas duas definições de expressões idiomáticas, passa-se à descrição de dois exemplos de unidades fraseológicas com zoônimos. 


\subsection{Apresentação, localização e equivalências de unidades fraseológicas com zoônimos}

Estar em papos de aranba

Encontrar a UFz estar em papos de aranha no Houaiss é difícil, uma vez que ela aparece no lema palpos, palavra desconhecida para a maioria dos consulentes. No Houaiss, no detalhamento dos verbetes e das informações técnicas (p. XXIV) em relação aos fraseologismos, informa-se que a ordem de entrada obedece a duas disposições: (1) a regra da preferência gramatical e a (2) regra da alfabetação das locuções dentro do verbete. Convém destacar para essa UFz a regra de preferência gramatical, a qual transcrevemos aqui:

(1) quanto à regra gramatical as locuções e frases feitas entram por seu substantivo ou por seu primeiro substantivo (ou qualquer palavra usada como tal). Quando não há substantivos entram por seu primeiro verbo; se não existirem essas duas classes, entram pelo seu primeiro adjetivo; caso não haja nenhuma destas três classes de palavras, pelo primeiro pronome; e em último caso, pelo primeiro advérbio. A ordem de preferência, portanto, é: substantivo, verbo, adjetivo, pronome, advérbio. (HOUAISS, p. XXIV)

Para o caso da UFz estar em papos de aranha, observamos que a mesma é usada preferencialmente com o verbo estar. Os consulentes, muito provavelmente, irão procurá-la por estar, pois é a primeira palavra ou pela palavra aranha, por ser o substantivo mais relevante da expressão (se comparado a palpo ou papo). Empreendeu-se a busca da expressão por aranha e, na acepção de $\mathrm{n}^{\mathrm{o}} 23$, após a marca de dialetismo vocabular regionalismo, consta a definição que explica ser a "aranha hesitante ou que facilmente se embaraça (diz-se de pessoa)".

Essa definição poderia parecer suficiente ao consulente, fazendo-o desistir de continuar a busca, uma vez que a definição liga-se ao sentido figurado da UFz. Mas supondo que continue a 
busca e a procure em papo, irá deparar-se com a UFz em papos de aranha na referência palpos de aranha, com a remissiva "ver o que se diz em uso no verbete palpo". Se o consulente continuar sua pesquisa, encontrará finalmente o fraseologismo (abaixo) seguido de sua definição e da advertência de que, no uso, palpo pode ser entendido como papo.

No dicionário Borba não há o registro dessa UFz em nenhum de seus lexemas.

\begin{tabular}{|c|c|}
\hline \multicolumn{2}{|c|}{ LíNGUA PORTUGUESA } \\
\hline Houaiss & Borba \\
\hline em palpos de aranha fig. em situação & \\
difícil (está em palpos de aranha com a & \\
falência) $\odot$ uso por se tratar de palavra & \\
terminológica, palpo é freq. entendido e us., & \\
na loc. em palpos de aranha, como se de & \\
papo se tratasse, num cruzamento com & \\
expressões do tipo estar no papo e de papo & \\
cheio (a língua aceita, porém,papose palpos, & \\
naquela expressão, como formas corretas). & \\
embaraçada (diz-se de pessoa); & \\
\hline
\end{tabular}

No dicionário de Borba, a ordenação dos fraseologismos como, por exemplo, soltar os cachorros ou estar no mato sem cachorro, obedece à preferência verbo como palavra-chave, o que pode levar o consulente a iniciar sua busca pelo verbo estar da UFz estar em papos de aranha.

\begin{tabular}{|l|l|}
\hline \multicolumn{1}{|c|}{ Borba } & \multicolumn{1}{|c|}{ Borba } \\
\hline SOLTAR & ESTAR \\
s. os cachorros enfurecer-se: & e. no mato sem cachorro \\
Diante de tanto disparate, Dona & encontrar-se em situação \\
Lúcia soltou os cachorros. & embaraçosa ou difícil: Se este guia \\
& nos abandonar, estamos num \\
& mato sem cachorro. \\
\hline
\end{tabular}


Welker (2004, p. 173) sugere que a ordenação seja feita pelo substantivo ou pelo verbo, afirmando que "bastaria fornecer a definição em apenas um verbete e que nos outros haveria remissões para este", e ressaltando que essa opção teria que vir indicada na introdução do dicionário.

Com respeito aos dicionários bilíngues pesquisados $(\mathrm{em}$ número de sete), apenas o Michaelis registra a UFz estar em palpos de aranha, em seu sentido figurado e oferece a paráfrase explicativa to be in a very difficult position após a marca pop (popular).

\begin{tabular}{|c|c|c|c|l|l|l|}
\hline \multicolumn{7}{|c|}{ LÍNGUA INGLESA } \\
\hline Larousse & Oxford & Longman & Michaelis & Collins & Webster's & Landmark \\
\hline & & & $\begin{array}{c}\text { pop to be in a } \\
\text { very difficult } \\
\text { position }\end{array}$ & & & \\
\hline
\end{tabular}

Sabe-se que a paráfrase explicativa não tem o mesmo efeito para a produção do aprendiz se a intenção dele for utilizar a linguagem coloquial. Tagnin (2005, p. 13) faz menção à UFz e traduz a mesma para o inglês com a UFz your goose is cooked. $\mathrm{O}$ tratamento dado à unidade fraseológica é satisfatório, pois é compatível com o registro e com a inclusão de um zoônimo, porém pensa-se que, caso o aprendiz queira utilizar essa expressão na versão de um texto da língua materna para a língua estrangeira, provavelmente terá dificuldade para utilizá-la, pois tentará vertêla a partir de "Eu estou em papos de aranha" e poderá chegar à construção "My goose is cooked", que não é corrente no inglês.

Pastore (2009, p. 206) traduz a UFz to have (bold) a wolf by the ears do inglês para o português como estar em papos de aranha, com o sentido de "estar em má situação". Considera-se que esse equivalente é mais apropriado para a produção porque tem características sintáticas similares à UFz de partida. $O$ aprendiz poderá chegar mais facilmente a I have a wolf by the ears, para a produção da frase Eu estou em papos de aranha. 
Estar entregue às baratas

Na tentativa de encontrar a UFz estar entregue às baratas, foi-se ao lema barata do Houaiss. Na parte reservada às locuções, encontrou-se entregue às baratas. Percebe-se, então, que a UFz foi registrada como entregue às baratas sem que nela fosse incluído o verbo estar. Essa ausência causa certo estranhamento, uma vez que para utilizar essa fraseologia o consulente tem, muito provavelmente, que combiná-la com o verbo estar ou ficar.

Ao procurar a UFz no dicionário de Borba, constata-se que a mesma está no lema barata e que aparece registrada como às baratas, sem verbo (estar e entregue). O sentido que essa UFz tem é o de "abandono", que é o mesmo oferecido nos dois dicionários monolíngues.

\begin{tabular}{|c|c|}
\hline \multicolumn{2}{|c|}{ LÍNGUA PORTUGUESA } \\
\hline Houaiss & Borba \\
\hline $\begin{array}{l}\diamond \text { entregue às b. infrrm. sem receber, ou } \\
\text { dar a si próprio, a devida atenção ou os } \\
\text { cuidados necessários; abandonado, } \\
\text { negligenciado < deprimido, passou o } \\
\text { dia entregue às b. }><\text { o museu está } \\
\text { entregue às b., com a falta de verba }>\end{array}$ & $\begin{array}{l}\text { às baratas às traças; ao } \\
\text { abandono: Quando chegou, } \\
\text { a chácara parecia entregue } \\
\text { às baratas. }\end{array}$ \\
\hline
\end{tabular}

O registro de UFz nos dicionários monolíngues requer o desenvolvimento de estudos mais aprofundados.

No que se refere aos sete dicionários bilíngues pesquisados, apenas o Larousse e o Collins registram essas UFz. O Larousse apresenta a UFz com o verbo estar e o Collins a registra sem esse verbo. Quanto ao sentido, os dois fazem referência ao "abandono à pessoa" ou ao "abandono a um projeto ou plano". O Collins registra a tradução empregando um zoônimo em sentido figurado. $\mathrm{O}$ Larousse emprega uma paráfrase explicativa formal para o sentido de projeto, construção. 


\begin{tabular}{|l|l|l|l|l|l|l|}
\hline \multicolumn{5}{|c|}{ LÍNGUA INGLESA } \\
\hline \multicolumn{1}{|c|}{ Larousse } & Oxford & Longman & Michaelis & \multicolumn{1}{|c|}{ Collins } & Webster's & Landmark \\
\hline $\begin{array}{l}\text { estar } \\
\text { entregue } \\
\text { às baratas } \\
\text { to let } \\
\text { oneself go; } \\
\text { [projeto, } \\
\text { construção] } \\
\text { to fall into a } \\
\text { state of } \\
\text { neglect. }\end{array}$ & & & & $\begin{array}{l}\text { entregue às } \\
\text { baratas } \\
\text { gone to the } \\
\text { dogs; (Plano) } \\
\text { gone out the } \\
\text { window. }\end{array}$ & & \\
& & & & & & \\
\end{tabular}

A equivalência gone to the dogs, do Collins, atende ao sentido figurado; porém, para fins de produção, essa característica pode ser problemática para o consulente. Suponhamos que ele tente fazer a versão da construção a casa estava entregue às baratas, em nível iniciante tentará colocar the bouse gone to the dogs; em nível avançado poderá fazer a construção the bouse was gone to the dogs, a qual é aceitável. A ferramenta do KWIC oferece as seguintes construções em inglês para essa UFz: Man, that shop bas really gone to the dogs - I don't even want to go inside any more. ou Now be was dead and everything was gone to the dogs, there was notbing but debt and threatening e, ainda, outra, "Going to the dogs" means going bad.

Essas construções mostram que as abonações e informações contrastivas são indispensáveis nos dicionários bilíngues didáticos para fins de produção, o que vem corroborar a proposta de Durão, ${ }^{1}$ que justifica a necessidade de desenvolvimento de pesquisas nessa área:

\footnotetext{
${ }^{1}$ DICIONÁRIO BILÍNGUE CONTRASTIVO DE UNIDADES FRASEOLÓGICAS (PORTUGUÊS-ESPANHOL) (DUFraPE), Projeto aprovado pelo CNPq com o mérito de produtividade em pesquisa. Autora: Profa. Dra. Adja Balbino de Amorim Barbieri Durão, UFSC.
} 
[...] para reduzir problemas existentes quanto à incorporação de lexias compostas e complexas em dicionários bilíngues dessas línguas, carências essas que vêm sendo constatadas em várias pesquisas e que não se consubstanciam, necessariamente, no número de publicações existentes, mas na inadequação das informações oferecidas em grande parte dessas publicações. (DURÃO, projeto Cnpq)

Com os exemplos analisados, tentou-se dar uma pequena amostra da pesquisa que estamos realizando com o propósito de contribuir para as reflexões que envolvem projetos lexicográficos que objetivem o fomento da produção dos aprendizes.

\section{Algumas considerações finais}

Procuramos apresentar neste artigo alguns resultados da pesquisa que começa a se desenvolver, a qual tem por meta identificar e analisar a presença de UFz em dicionários monolíngues e seus equivalentes em dicionários bilíngues, no que diz respeito ao estudo dos zoônimos (na direção português-inglês).

\section{Referências}

BÉJOINT, H. Tradition and innovation in modern English dictionaries. Oxford: Oxford University Press, 1994.

CARVALHO, O. L. de S. Lexicografia bilíngue português-alemão: teoria e aplicação à categoria das preposições. Brasília: Thesaurus, 2001.

HALLIDAY, M. A. K.; YALLOP, C. Lexicology: a short introduction. London: Cromwell Press, 2007.

HARTMANN, R. R. K. Interlingual lexicograpby. Tübingen: Max Niemeyer Verlag, 2007.

NIDA, E. A. Towards a science of translating. Leiden: E. J. Brill, 1964.

PASTORE, P. C. F. A. A simbologia dos animais em expressões idiomáticas Inglês-Português: uma proposta lexicográfica. 2009. Tese (Doutorado) - UNESP - São José do Rio Preto, 2009. 
TAGNIN, S. O. Expressões idiomáticas e convencionais. São Paulo: Ática, 1989.

TAGNIN, S. O. O jeito que a gente diz: expressões convencionais e idiomáticas. São Paulo: Disal, 2005.

WERNER, R.; DURÃO, A. B. de A. B. Dicionários bilíngues de línguas afins. Florianópolis, 2012. (Palestra proferida no I Simpósio Internacional de Lexicografia e Linguística Contrastiva, realizado em Florianópolis, na Universidade Federal de Santa Catarina, no período de 3 a 4 de dezembro de 2012).

XATARA, C. M. Tipologia das expressões idiomáticas. Alfa, São Paulo, v. 42, p. 169-176, 1998.

ZGUSTA, L. Translational Equivalence in the Bilingual Dictionary. In: HARTMANN, R. R. K. (Ed.). LEXeter'83 Proceedings - Papers from the International Conference on Lexicography at Exeter, 9-12 Sep. 1983. Tübingen: Niemeyer, p. 147-154, 1984.

ZGUSTA, L. Manual of Lexicography. Paris: Mounton, 1971.

\section{Apêndice}

\section{Dicionários monolíngues}

COLLINS Dicionário prático, Inglês-Português/ Português-Inglês. 3. ed. Disal, 2012.

Dicionário HOUAISS da língua portuguesa. Editora Objetiva, 2007.

Dicionário OXFORD escolar para estudantes brasileiros de inglês (nova edição) Português-inglês/Inglês-português. ed. revisada. Oxford: Oxford University Press, 2009.

Dicionário UNESP do português contemporâneo. Francisco S. Borba, Beatriz Nunes de Oliveira Longo, Maria Helena de Moura Neves, Marina Bortolotti Bazzoli \& Sebastião Expedito Ignacio. São Paulo: Editora UNESP, 2013. 1489p. 


\section{Dicionários escolares bilíngues português/inglês}

LANDMARK Dictionary, English-Portuguese/Portuguese-English. Richmond Publishing/Editora Moderna, 2006.

LAROUSSE Dicionário prático para o aprendizado da língua inglesa (avançado). 2. ed. São Paulo: Larousse do Brasil, 2009.

LONGMAN Dicionário escolar Inglês - Português / Português-Inglês, para estudantes brasileiros. 2. ed. Longman, 2009.

MICHAELIS DICIONÁRIO escolar Inglês-Português/ Português-inglês. 2. ed. Melhoramentos, 2010.

MINI-WEBSTER'S Dicionário, Inglês-Português/ Português-Inglês, Antonio Houaiss, Record, 2011.

Recebido para publicação em 27 de junho de 2013 Aprovado em 2 de outubro de 2013 